\title{
Sex identification and biomass reconstruction from the cuttlebone of Sepia officinalis
}

\author{
Eduardo Almonacido-Rioseco*,Vicente Hernández-García ${ }^{\dagger}$,Aldo P. Solari†, Ángelo Santana del Pino ${ }^{\dagger}$ \\ and José J. Castro ${ }^{\dagger \ddagger}$
}

*Biota Austral Consultores, C/ Francisco Bilbao 940, Casilla de correo 19, Punta Arenas, Chile. Huniversidad de Las Palmas de Gran Canaria, Edificio de Ciencias Básicas, Campus de Tafira, 35017 Las Palmas de Gran Canaria, Canary Islands, Spain. ${ }^{\ddagger}$ Corresponding author, e-mail: jcastro@pesca.gi.ulpgc.es

\begin{abstract}
Significant differences were found between males and females in the fragmocone, external cone and widths of the cuttlebone in Sepia officinalis caught in the small-scale trap fishery off Gran Canaria Island (Spain). It is suggested that: (a) differences may depend on morphological adaptations of females for egg laying; (b) cuttlebones represent over the $50 \%$ of the total cuttlefish caught (which is unrecorded in the fishery); and (c) the relationships between several morphometric measures of the cuttlebone and the mantle length and wet weight may allow more accurate biomass estimations of this species in the fishery.
\end{abstract}

\section{INTRODUCTION}

There are few hard structures with taxonomic relevance in cephalopods, but it has not been an obstacle to develop a specific method of classification of this group of species (Clarke, 1962; 1986). In particular, the cuttlefish is characterized by an internal shell (the cuttlebone), as skeleton, constituted by a porous matrix of calcium carbonate that plays an important role in the control of flotation (Richard, 1972). Boletzky (1974, 1983) suggested that the cuttlebone of Sepia officinalis, in natural conditions, presents a sexual differentiation being wider in females than in males and this difference is accentuated in starved animals.

In fishery studies, the cuttlebone may be a common component in the catches and it is discarded. For instance, in the small-scale trap fishery off Gran Canaria Island (Spain), the cuttlebone may represent approximately the $50 \%$ of total Sepia caught (Almonacid-Rioseco, 2006), which is unrecorded in the landings. In this sense, the biomass and several biometric characteristics can be estimated according to the relationships between the measurements of some parts of the cuttlebone and the mantle length of the animal. In this way, it is possible to obtain specific equations for a certain area, which is of

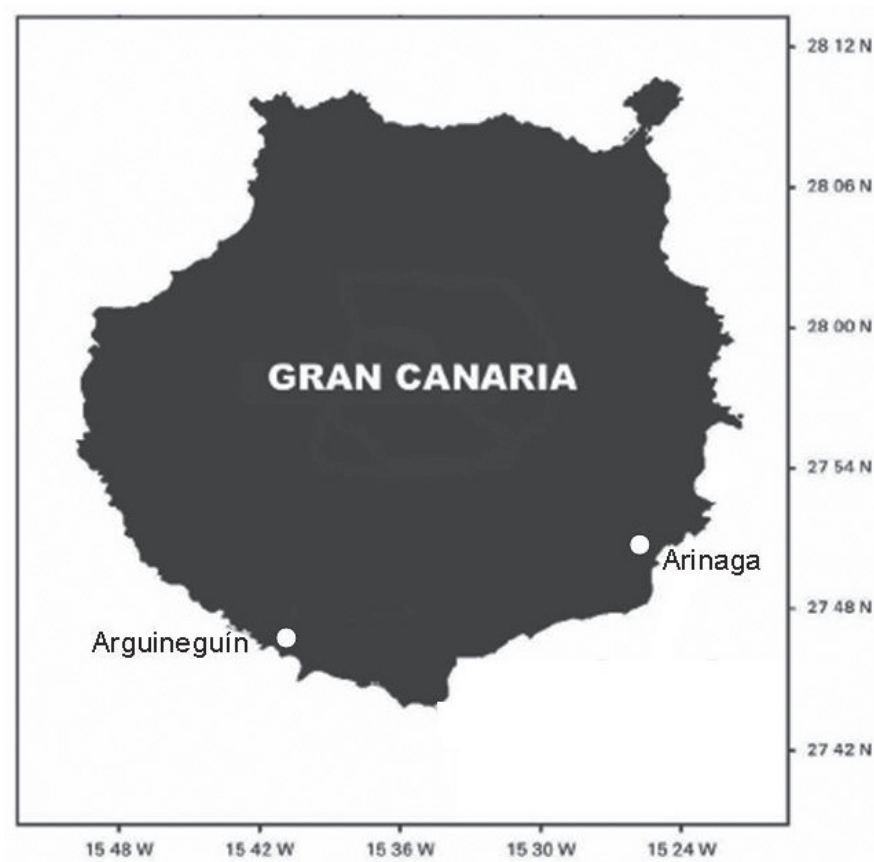

Figure I. Geographical situation of the sampling ports at the Gran Canaria Island (Canary Islands, Spain, central-east Atlantic). importance in species with high geographical variability such as Sepia officinalis.

The results obtained in this work could be of practical application and are of interest in order to implement both the assessment and management of the fishery.

The aim of this study was to determine the morphometric relationships between the cuttlebone and the dorsal mantle length (DML) and wet weight of the cuttlefish in relation to both of the sexes as we have observed a high proportion of this hard structure in the catches, particularly when the deployment of the traps surpass four days of fishing.

\section{MATERIAL AND METHODS}

We analysed 426 cuttlefish ( 320 males and 106 females) obtained from commercial catches landed at the Arguineguín and Arinaga ports (south-west and south-east of the island of Gran Canary, respectively; Figure I) by the small-scale trap fishery between November 2002 and November 2004. 
The morphometric features recorded, according with Roper and Voss (1983) were: (a) the dorsal mantle length (DML), wet weight $(W)$ and sex of each individual; (b) once eviscerated, the length $(\mathrm{CL})$, height $(\mathrm{CH})$ and width $(\mathrm{CW})$ of the cuttlebone and $(\mathrm{c})$ the length and width of the fragmocone (FL and FW respectively), and the width of the internal (ICW) and external (ECW) cones, with an accuracy of $0.05 \mathrm{~mm}$ (Figure 2). The cuttlebone was also weighed (CTW) with an accuracy of $0.01 \mathrm{~g}$.

With the aim to determine the sex from the measurements of the cuttlebone, we used discriminating analysis with the inclusion method by steps (Pérez-López, 200I).This procedure generated a function based on the linear combinations of the prediction variables that gave better discrimination between males and females. The function was estimated by using 426 individuals in which sex was previously known. Also, the relationships between DML, weight and the measurements of the cuttlebone of both sexes were determined through linear regression. Furthermore, we used multiple regressions taking into account the sexes and their contribution to each sample according to the corresponding independent variable. From this method, it was possible to estimate an equation for the complete sample (without sex distinction), and for each sex. Calculations were carried out using the SPSS software (version II.0.I), and with an $\alpha$ lower than 0.05 .

\section{RESULTS \\ Sex identification}

Using the aforementioned variables, it was possible to differentiate the cuttlebones of males of those of females, with an accuracy of $91.8 \%$, following the Equation I.
$f(x)=0.48 \mathrm{I}(\mathrm{CW})+0.2 \mathrm{I} 5(\mathrm{ECW})+0.18 \mathrm{I}(\mathrm{FW})-0.189(\mathrm{CH})-$ $0.108(\mathrm{CL})-0.089(\mathrm{FL})-1.552$
(Eqn. I)

The mean distance between centroids (C) was 0.66 . Cuttlebones belonged to males and females as $f(x)$ was lower and higher than $\mathrm{C}$, respectively.

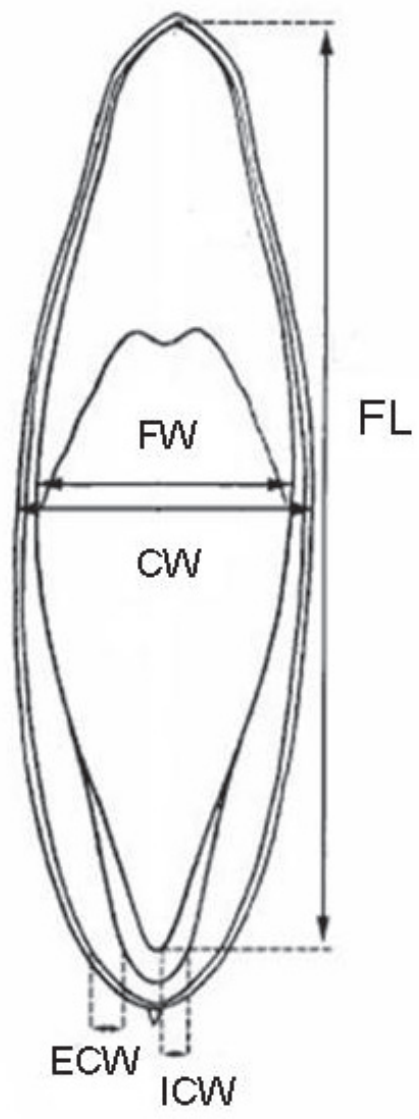

Ventral view

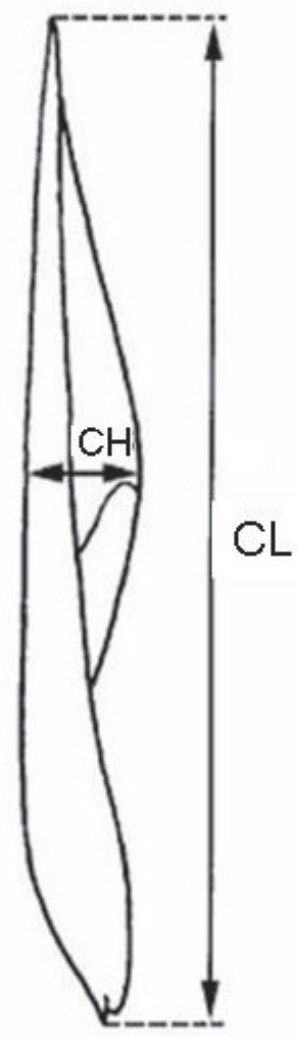

Lateral view

Figure 2. Morphometric measures taken on the cuttlebone of Sepia officinalis: length $(\mathrm{FL})$ and widths of the fragmocone $(\mathrm{FW})$, cuttlebone $(\mathrm{CW})$, external cone $(E C W)$ and internal cone $(I C W)$ (ventral view). Length $(C L)$ and high $(C H)$ of the cuttlebone (lateral view).

\section{Morphometric relationships}

The parameters of the estimated relationships between the different measures of the cuttlebone and the body wet weight for both sexes are shown in Tables I and 2.

Using the Analysis of Variance (ANOVA), it was determined that the CW $(F=5.219, P<0.05)$, FW $(F=5.946, P<0.05)$ and ECW $(F=10.123, P<0.05)$ were variables that may reflect some of the morphometric differences between the sexes. The results obtained indicated that these measures are proportionally larger in females than in males, being more accentuated in the bigger specimens (Figures 3 \& 4).

Table I. Parameters of the potential fitting equations between morphometric variables of the cuttlebone and the dorsal mantle length (DML) of males Sepia officinalis.

\begin{tabular}{|c|c|c|c|c|c|c|}
\hline Variable & $\mathrm{a}$ & $\begin{array}{c}\text { a } \\
\text { Standard } \\
\text { error }\end{array}$ & b & $\begin{array}{c}\text { B } \\
\text { Standard } \\
\text { error }\end{array}$ & $\mathrm{R}^{2}$ & $\mathrm{~F}$ \\
\hline $\mathrm{FL}$ & 0.0004 & 0.0001 & 2.8074 & 0.0270 & 0.97 & 10855.6 \\
\hline FW & 0.0082 & 0.0329 & 2.8724 & 0.0329 & 0.96 & 7623.5 \\
\hline$C W$ & 0.0048 & 0.0005 & 2.9075 & 0.0272 & 0.97 & I I 443.I \\
\hline ICW & 38.3409 & 2.9640 & 1.4704 & 0.0519 & 0.72 & 804.0 \\
\hline ECW & $2.594 I$ & 0.3748 & 2.0246 & 0.0602 & 0.78 & 1132.7 \\
\hline $\mathrm{CH}$ & 0.7150 & 0.0663 & 2.1532 & 0.0325 & 0.93 & 4398.0 \\
\hline $\mathrm{CL}$ & 0.0005 & 0.0001 & 2.7142 & 0.0244 & 0.98 & 12403.2 \\
\hline W & 35.6102 & 0.9095 & 0.9141 & 0.0102 & 0.96 & 7963.4 \\
\hline
\end{tabular}

Table 2. Parameters of the potential fitting equations between morphometric variables of the cuttlebone and the dorsal mantle length (DML) of females Sepia officinalis.

\begin{tabular}{|c|c|c|c|c|c|c|}
\hline Variable & a & $\begin{array}{c}\text { a } \\
\text { Standard } \\
\text { error }\end{array}$ & b & $\begin{array}{c}\text { b } \\
\text { Standad } \\
\text { error }\end{array}$ & $\mathrm{R}^{2}$ & $\mathrm{~F}$ \\
\hline $\mathrm{FL}$ & 0.0005 & 0.0001 & 2.7631 & 0.0440 & 0.97 & 3947.8 \\
\hline FW & 0.0099 & 0.0020 & 2.7805 & 0.0553 & 0.96 & 2528.1 \\
\hline $\mathrm{CW}$ & 0.0061 & 0.0013 & 2.8079 & 0.0534 & 0.96 & 2770.1 \\
\hline ICW & 37.3514 & 5.5744 & 1.4258 & 0.0968 & 0.68 & 217.2 \\
\hline ECW & 2.8523 & 0.5885 & 1.9153 & 0.0832 & 0.84 & 529.9 \\
\hline $\mathrm{CH}$ & 0.4033 & 0.0623 & 2.3763 & 0.0548 & 0.95 & 1881.3 \\
\hline$C L$ & 0.0004 & 0.0001 & 2.7451 & 0.0421 & 0.98 & 4248.1 \\
\hline W & 33.6104 & 9.3410 & 24.3931 & 0.5955 & 0.94 & 1677.8 \\
\hline
\end{tabular}



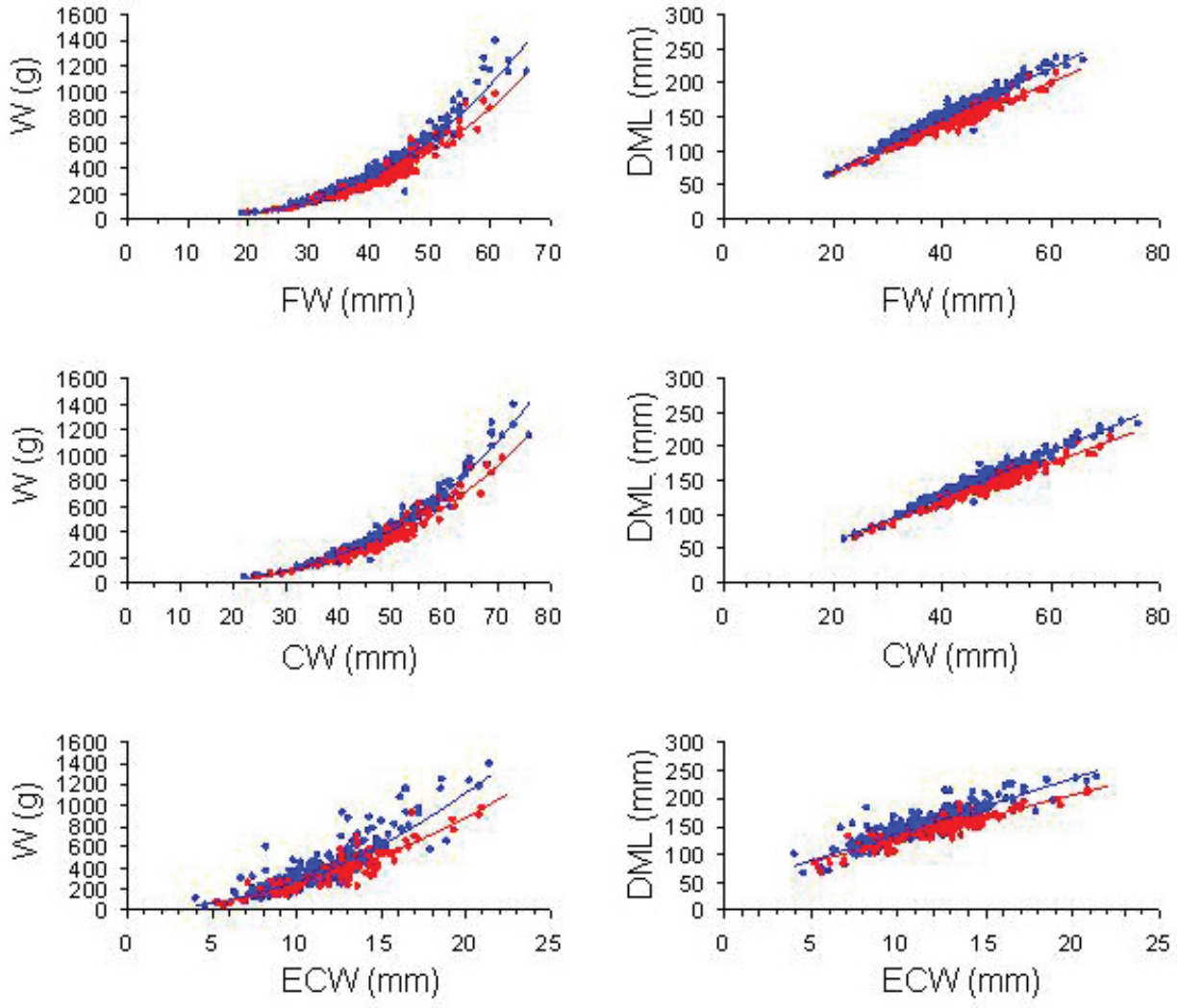

\section{- Males}

\section{- Females}

Figure 3. Relationships of wet weight (W) and length (DML) with the widths of the fragmocone (FW), cuttlebone (CW) and the external cone (ECW) for males and females cuttlefish caught off Gran Canaria.
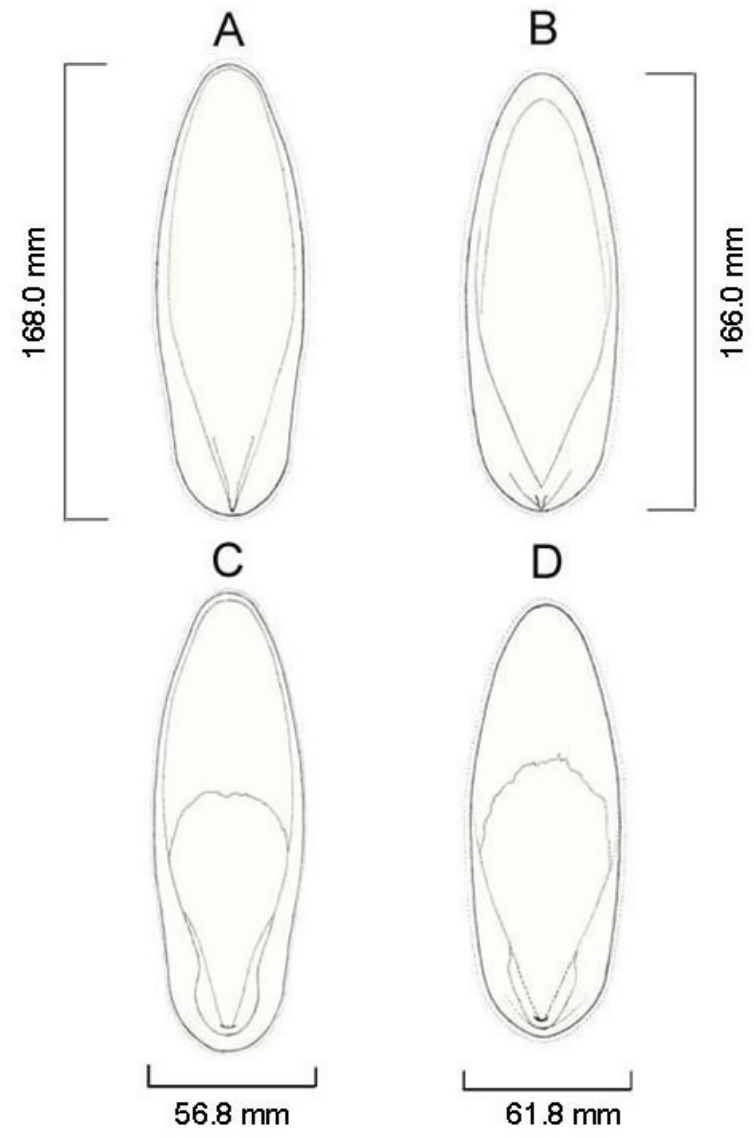

Figure 4. Dorsal and ventral views of the cuttlebones of the adult male $(A, C)$ and female $(B, D)$. 


\section{DISCUSSION}

We have observed that, in the fishing grounds used by the artisanal fleet that operate with fish traps off the Canary Islands (Hernández-García et al., 1998), a major proportion (>50\%) of the Sepia officinalis caught is observed in form of cuttlebones. This may be due to mortality in the fishing trap caused by predation by other cephalopods (Sepia and Octopus) and/or sparids and monacanthids fishes. Due to this, it may be of great relevance to take the cuttlebones into account and convert their numbers to biomass and fishing mortality estimations.

The morphometric measures of the cuttlebone were analysed having into account the possible differences due to sex, and considering the depth range where the cuttlefish were caught. In this way, Bandel \& Boletzky (1979) and Gower \& Vincent (1996) suggested that the form and level of compactness of the cuttelbone depend of the depth where the animals live as pressure directly affects the form and the interlamellar space in the fragmocone. Also, the differences found between males and females in FW, CW and ECW, are explained from the phylogenetic point of view (Hewitt \& Stait, 1988; Sainz, 1990) as females have developed adaptations that permit them to obtain a major surface to lodge the eggs. This adaptation of the female anatomy may be described by a relationship of a wider cuttlebone (relative to males) in relation with the body length.

The cuttlebone growth pattern strongly depends on the temperature oscillations, availability of nutrients, and depths where the animals live (Choe, 1963; Richard, 1969; 1972; Boletzky, 1974; Natsukari et al., 1991; Ré \& Narciso, 1994; Le Goff et al., 1998; Bettencourt \& Guerra, 200I). However, there is not evidence that shows that these factors may alter the morphometric features of the cuttlebone in a different way depending on the sex. This structure has traditionally been used in taxonomic studies to identify species according to the morphological variations and their sexual dimorphism (Lu, 1998; Neige, 2006).

The results obtained in the present study may allow developing a useful tool for both: (a) the estimation of the total biomass caught of Sepia officinalis; and (b) determination of the fishing mortality generated by the small-scale trap fishery. This may be possible due to the direct biometric relationships between the cuttlebone and the length and weigh in Sepia. Also, the presence of cuttlebone parts (from which the length, weight and sex of the eaten cuttlefish may be determined) in the stomach contents predators such as marine turtles, may further allow to determine the impact of these species on the cuttlefish population.

We would like to thanks to Alejandro y Ulises Medina (fishermen in Arguineguín, Gran Canaria) for their collaboration in the sample collection, and Ms. Angela Caballero for her assistance in the laboratory. Dr. Ángel Guerra (CSIC,Vigo, Spain) is acknowledged for his helpful suggestions and comment on this work.

\section{REFERENCES}

Almonacid-Rioseco, E. 2006. Contribución a la ecología de Sepia officinalis (Cephalopoda: Sepiidae) en Gran Canaria. Mem. Tesis Doctoral. Universidad de Las Palmas de Gran Canaria. Spain. 167 pp.

Bandel, K. \& Boletzky, S.v., 1979. A comparative study of chambered cephalopod shells. Veliger, 2 I, 3I 3-354.

Bettencourt, V. \& Guerra, A., 200I. Age studies based on daily growth increments in statoliths and growth lamellae in cuttlebone of cultured Sepia officinalis. Marine Biology, I39, 327-334.

Boletzky, S.v., 1974. Effects de la Sous-nutrition prolongée sur le développement de la coquille de Sepia officinalis L. (Mollusca, Cephalopoda). Buletin de la Société Zoologique de France, 99, 667-673.

Boletzky, S.v., 1983. Sepia officinalis. In Boyle, P.E. (Ed.), Cephalopod life cycles. London: Academic Press Ltd.Vol I, Pp. $31-53$.

Choe, S., 1963. Daily age marking on the shell of cuttlefishes. Nature, London, 197, 306-307.

Clarke, M.R., 1962. Significance of cephalopods beaks. Nature, London, 193, 560-56I.

Clarke, M.R., 1986. A handbook for the identification of cephalopod beaks. Oxford, UK: Clarendon Press, 273 pp.

Gouver, D. \& Vincent, F.V., 1996. The mechanical design of the cuttlebone and its bathymetric implications. Biomimetics, 4, 37-57.

Hernández-García,V., Hernández-López,J.L. \& Castro,J.J., 1998.The octopus (Octopus vulgaris) in the small-scale trap fishery off the Canary Islands (central-east Atlantic). Fisheries Research, 35, 183-189.

Hewitt, R.A. \& Stait, B., 1988. Seasonal variation in septal spacing of Sepia officinalis and some Ordovician actinocerid nautiloids. Lethaia, I I, 383-394.

Le Goff, R., Gauvrit, E., Pinzon du Sel, G. \& Daguzan, J., 1998. Age group determination by analysis of the cuttlebone of cuttlefish Sepia officinalis L. in reproduction in the bay of Biscay.Journal of Molluscan Studies, 64, 183-193.

Lu, C.C., 1998. Use of sepion in the taxonomy of Sepiidae (Cephalopoda: Sepioidea) with an emphasis on the Australian fauna. In Voss N. A. Vecchione M., Toll R. B., Sweeney M. J. (Eds.) Systematics and biogeography of cephalopods. Smithsonian Contribution to Zoology, 586, 207-2I4.

Natsukari, Y., Hirata, S. \& Washizaki, M., 199I. Growth and seasonal changes of cuttlebone characters of Sepia esculenta. In Boucaud-Camou E. (ed.). Actes du premier symposium international sur la seiche. Université de Caen. pp. 49-67.

Neige, P., 2006. Morphometrics of hard structures in cuttlefish. Vie et Milieu, 56, I2I-127. 
Pérez-López, C., 200I. Técnicas Estadísticas con SPSS ${ }^{\circledR}$. Madrid, España: Prentice Hall 57I pp.

Ré, P., Narciso, L., 1994. Growth and cuttlebone microstructure of juvenile cuttlefish, Sepia officinalis L., under controlled conditions. Journal of Experimental Marine Biology and Ecology, 177, 73-78.

Richard, A., 1969. The part placed by temperature in the rhythm of formation of markings on the shell of cuttlefish (Sepia officinalis L.) (Cephalopoda, Mollusca). Experientia, 25, I05I-I052.

Richard, A., 1972. La coquille de Sepia officinalis: Series et interstries, leurs variations en rapport avec l'ecologie de l'animal. Haliotis, 2, 195-202.

Roper, C.F.E. y G.L. Voss. 1983. Guidelines for taxonomic descriptions of cephalopod species. Memoirs of the National Museum of Victoria, 44, 49-63.

Sainz, J., 1990. Cuttlebone development in Sepia officinalis. 1990. Pacific Science. Abstract of papers, 44, I94-195.

Submitted 19 September 2007. Accepted 24 March 2008. 